\title{
Prevention of postoperative deep vein thrombosis with dipyridamole and aspirin
}

\author{
J T G RENNEY， E F O'SULLIVAN， P F BURKE
}

\section{Summary}

One hundred and sixty patients have been studied in a controlled trial of two drugs which have been used in combination to prevent postoperative deep-vein thrombosis. Both the drugs, dipyridamole (Persantin) and aspirin, were given by mouth from the evening before operation and for seven days after operation. The radioactive fibrinogen test was used to diagnose thrombosis. Of the 85 patients in the control group 24 developed thrombosis $(28 \%)$. Twelve out of 85 patients $(14 \%)$ in the test group were found to have thrombosis. Similar significant differences in incidence were found in the various subgroups.

\section{Introduction}

In 1846 Virchow $^{1}$ stated that venous thrombosis was caused by changes in one or more of three important factors-namely, blood flow, venous endothelium, and the clotting mechanism. Recent methods of preventing postoperative deep vein thrombosis (DVT) have been based on the concept that one of the members of "Virchow's triad" is of prime importance in the prevention of thrombosis. In this study we were particularly concerned with the clotting mechanism.

The introduction of the radioactive fibrinogen test ${ }^{2}$ and its refinement by the use of the Pitman portable ratemeter ${ }^{3}$ have made the assessment of various prophylactic measures more accurate and have enabled workers to study many patients in a short period. Any prophylactic treatment aims to prevent venous thrombosis with complications and hence decrease the incidence of pulmonary embolism, which is the commonest cause of death in hospital patients. ${ }^{4}$

Recently the platelet has been studied in its role as initiator in the thrombotic process. ${ }^{5}$ Bygdeman et al ${ }^{6}$ thought that there was a causal relation between an increase in platelet adhesiveness after operation and the onset of venous thrombosis. But Negus et $\mathrm{al}^{7}$ and Flute et $a l^{8}$ could not show a correlation between DVT and either preoperative or maximum postoperative platelet adhesiveness. In most of the studies in which changes in platelet adhesiveness were related to thrombosis, however, the adhesiveness was usually assessed by the retention of platelets in a glass bead column, and we do not know which aspect of platelet function is being examined in such tests.

Anatomical studies 910 have identified platelet thrombi in venous valve cusps in the thigh or the calf, and it is suggested that in patients who have had operations small platelet-fibrin complexes become adherent to damaged venous endothelium and disturb the blood flow, and that biochemical interaction

\footnotetext{
Department of Surgery (University of Melbourne), St Vincent's Hospital, Fitzroy, Victoria, Australia

J T G RENNEY, FRCs, FRACs, second assistant

P F BURKE, MB, BS, research assistant

Department of Medicine (University of Melbourne), St Vincent's Hospital, Fitzroy, Victoria, Australia

E F O'SULLIVAN, FRACP, associate
}

between platelets and the coagulation mechanism is the key to thrombus growth. ${ }^{11}$ Blood flow is sluggish in patients under general anaesthesia and when people are supine. ${ }^{12}$ This local hypercoagulable state, together with venous stasis, ensures further propagation of thrombus.

Conventional anticoagulation, which aims to prevent further propagation of thrombus, has inherent complications. Low-dose subcutaneous heparin has been shown to be effective in preventing postoperative DVT. In low concentrations, however, heparin also selectively blocks the induction of aggregation of platelets by thrombin, ${ }^{1314}$ and in higher concentrations inhibits the "release reactions" that are essential to the formation of plateletfibrin complexes. These "antiplatelet" actions of heparin may play a part in the prevention of thrombosis.

Hence treatment after operation may be aimed at decreasing the ability of the platelet to initiate thrombosis. Emmons et al ${ }^{15}$ studied the effect of dipyridamole on platelet function in vitro and found a significant depression of the aggregation reactions. Sullivan et al ${ }^{16}$ successfully used dipyridamole combined with anticoagulants to prevent the thromboembolic complications after heart valve replacement, but Salzman et $a l^{17}$ found that dipyridamole alone, though reducing the incidence of postoperative thrombosis, was not as effective as aspirin or oral anticoagulants.

We therefore decided to combine the two drugs-aspirin, which acts on platelet adhesion and collagen- and adrenalineinduced aggregation, as well as causing some depression of the secondary wave of aggregation induced by adenosin diphosphate $(A D P)^{18}$-and dipyridamole, which is effective against the aggregation induced in vitro by ADP. These agents were used in a controlled trial to assess the effectiveness of this form of treatment in preventing postoperative DVT.

\section{Patients and methods}

All of the 160 patients included in the study were over the age of 40 and underwent elective general surgical operations in the wards of the university department of surgery. Patients who were undergoing surgery on the leg or on the thyroid gland were excluded from the study. Patients were randomly allotted to a control or treatment group. All patients received routine hospital physiotherapy before and after operation and were encouraged to become ambulant as soon as possible after operation.

The treatment group received by mouth calcium aspirin $1 \mathrm{~g}$ and dipyridamole (Persantin) $100 \mathrm{mg}$ on the evening before operation. The same dose of each drug was administered by mouth for seven days after operation or until the patient was discharged from hospital. Suppositories were used in patients who could not tolerate, or could not be given, orally administered preparations.

Diagnosis of DVT-All patients were screened with the ${ }^{125} \mathrm{I}-$ fibrinogen test using a Pitman-235 isotope localisation monitor. The radioactive fibrinogen was supplied by the Radio-chemical Centre, Amersham, England. Each patient was given $100 \mu \mathrm{Ci}$ of radioactive fibrinogen intravenously immediately after the operation. Before operation the thyroid gland was "blocked" with oral sodium iodide mixture and this was continued for two to three weeks postoperatively. The patients' legs were scanned on the first, third, and sixth days after operation. If the calves showed a positive scan at any time the legs were then scanned daily for up to 10 days. The radioactive count in various positions on the legs was expressed as a direct percentage of the heart count. Patients were considered to have a DVT when an increase of $20 \%$ was observed at the same place on two different days or between two adjacent sites, provided this increase persisted for more than 24 hours. 


\section{Results and comment}

There were 75 patients in the control group and 85 in the treatment group. The two groups were comparable in age distribution, sex ratio, and the types of operation performed. The incidence within both groups of the various factors that predispose to the development of DVT $^{19}$ was comparable (table I).

TABLE I-Predisposing factors among 75 controls and 85 treated patients. Results are numbers (percentages) of patients

\begin{tabular}{l|c|c|c|c|c}
\hline \multicolumn{1}{c|}{ Group } & Obesity & $\begin{array}{c}\text { Varicose } \\
\text { veins }\end{array}$ & Malignancy & $\begin{array}{c}\text { Previous } \\
\text { DVT }\end{array}$ & $\begin{array}{c}\text { Previous } \\
\text { pulmonary } \\
\text { embolism }\end{array}$ \\
\hline $\begin{array}{l}\text { Control } \\
\text { Treatment }\end{array}$ & $\begin{array}{c}28(37 \cdot 3) \\
34(40 \cdot 0)\end{array}$ & $\begin{array}{c}11(14 \cdot 7) \\
17(20 \cdot 0)\end{array}$ & $\begin{array}{c}38(50 \cdot 7) \\
\mathbf{4 4}(51 \cdot 8)\end{array}$ & $\begin{array}{c}\mathbf{4}(5 \cdot 3) \\
7(8 \cdot 2)\end{array}$ & $\begin{array}{c}1(1 \cdot 3) \\
0\end{array}$ \\
\hline
\end{tabular}

TABLE II-Incidence of thrombosis in both groups

\begin{tabular}{|c|c|c|c|c|c|}
\hline \multirow{2}{*}{ Group } & \multirow{2}{*}{$\begin{array}{c}\text { No of } \\
\text { patients }\end{array}$} & \multirow{2}{*}{$\begin{array}{l}\text { No with } \\
\text { DVT }\end{array}$} & \multirow{2}{*}{$\begin{array}{c}\text { No of } \\
\text { bilateral } \\
\text { thromboses }\end{array}$} & \multicolumn{2}{|c|}{ No of unilateral thromboses } \\
\hline & & & & Right & Left \\
\hline $\begin{array}{l}\text { Control } \\
\text { Treatment }\end{array}$ & $\begin{array}{l}75 \\
85\end{array}$ & $\begin{array}{l}24\left(32{ }^{\prime \prime}{ }_{10}\right) \\
12\left(14{ }^{\prime \prime},{ }_{11}\right)\end{array}$ & $\begin{array}{r}14 \\
7\end{array}$ & $\begin{array}{l}3 \\
1\end{array}$ & $\begin{array}{l}7 \\
4\end{array}$ \\
\hline
\end{tabular}

Table II shows the overall incidence of DVT in the control and treatment groups. Fourteen of the 24 patients with DVT in the control group and seven of the 12 patients with DVT in the treatment group had positive bilateral leg scans. The difference was significant $(0.01<P<0.02)$.

Malignancy is considered to be a strong disposing factor to the development of DVT. In the control group $50 \%$ of the patients had malignancy (table I), and there was a similar proportion in the treatment group. The incidence of thrombosis in those patients who had malignancy was 12 out of 38 patients $(31.6 \%)$ in the control group, and 5 out of 44 patients $(11.4 \%)$ in the treatment group. This difference was significant. The proportion of men and women in the control and treatment groups was also comparable; the incidence of DVT was $33.3^{\circ}$ in the female control patients and $15.5 \%$ in the female treated patients. Among the men the incidence of DVT was $29.6 \%$ and $11 \cdot 1 \%$ respectively. These differences were also significant.

Consideration of the type of operation in the 75 control patients showed that 6 of the $13(46.2 \%)$ patients undergoing biliary surgery; 4 of the $15(26.7 \%$ ) patients undergoing bilateral adrenalectomy or oophorectomy, or both; and 4 of the 8 patients $(50 \%)$ undergoing gastric surgery $\left(50^{\circ}\right)$ developed postoperative DVT (table III). In the treatment group there was a general decrease in the incidence of DVT; in particular, only two of the 14 patients $(14.3 \%$ ) undergoing biliary surgery and 3 of the 23 patients $(13.0 \%$ ) undergoing bilateral adrenalectomy or oophorectomy, or both, developed postoperative DVT (table III). One patient in each group developed clinical signs of pulmonary embolism and in each of these patients radioactivity extended into the popliteal or lower femoral veins.

TABLE III-Incidence of DVT in both groups according to type of operation

\begin{tabular}{|c|c|c|c|c|}
\hline \multirow[b]{2}{*}{ Operation } & \multicolumn{2}{|c|}{ Control group } & \multicolumn{2}{|c|}{ Test group } \\
\hline & $\begin{array}{l}\left.\text { No }\left({ }^{\prime \prime},\right)_{1}\right) \text { of } \\
\text { patients }\end{array}$ & $\begin{array}{c}\left.\text { No (" }{ }_{\text {DVT }}\right) \text { with } \\
\end{array}$ & $\begin{array}{l}\text { No }\left({ }^{0}{ }_{0}\right) \text { of } \\
\text { patients }\end{array}$ & 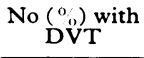 \\
\hline $\begin{array}{l}\text { Gastric } \\
\text { Colonic } \\
\text { Biliary } \\
\text { Laparotomy } \\
\text { Bilateral adrenalectomy } \\
\text { and oophorectomy } \\
\text { Mastectomy } \\
\text { Miscellaneous }\end{array}$ & $\begin{array}{r}8(10 \cdot 7) \\
9(12 \cdot 0) \\
13(17 \cdot 3) \\
8(10 \cdot 7)\end{array}$ & $\begin{array}{l}4(50 \cdot 0) \\
2(22 \cdot 2) \\
6(46 \cdot 2) \\
3(37 \cdot 5)\end{array}$ & $\begin{aligned} & 9(10 \cdot 6) \\
& 10(11 \cdot 8) \\
& 14(16 \cdot 5) \\
& 4(4 \cdot 7) \\
& 23(27 \cdot 1) \\
& 4(4 \cdot 7) \\
& 21(24 \cdot 7)\end{aligned}$ & $\begin{array}{l}1(11 \cdot 1) \\
2(20 \cdot 0) \\
2(14 \cdot 3) \\
1(25 \cdot 0)\end{array}$ \\
\hline
\end{tabular}

Bleeding complications-Excessive blood loss during or after operation was not a problem in any patient in the test group, nor were there any prominent haematomas in the postoperative period or serous leaks from any of the wounds.

Platelet function studies-The platelet adhesiveness was greatly decreased in patients on dipyridamole and aspirin-that is, an in-vitro effect could be shown. There was no difference in the platelet count in the two groups, nor a significant change in the packed cell volume.
The platelet aggregation reactions were studied before and on the fourth day after operation. These showed the expected changes, except in two patients, both of whom had evidence of DVT, and on further questioning it was found that these patients had not been given their treatment; they were withdrawn from the trial.

\section{Discussion}

Since the introduction of the radioactive fibrinogen test the magnitude of the problem of postoperative DVT has been underlined. Correlation with phlebography has confirmed that this test is an accurate and quick method for assessing the incidence and site of thrombi in postoperative patients. The relative ease and simplicity of the test enables many patients to be studied in a short time.

In general surgical patients the thrombi nearly always start in the soleal sinuses of the calf, where stasis occurs in the anaesthetized patient. ${ }^{12}$ If the thrombosis is limited to the soleal veins and the deep tibial veins the risk of pulmonary embolism is low; but once thrombus extends into the popliteal and lower femoral veins the risk of pulmonary embolism increases. ${ }^{20}$ It is important therefore to prevent postoperative DVT whenever possible and limit propagation should a calf thrombus develop.

Our results have shown that the combination of dipyridamole and aspirin significantly decreases the incidence of postoperative DVT as detected by the radioactive fibrinogen test in general surgical patients. Even in those patients with the greatest tendency to develop thrombosis, such as elderly patients having major operations, dipyridamole and aspirin reduced the incidence of DVT significantly. There were no complications from the administration of the drugs, and there was no difficulty in administering the calcium aspirin, which could be given in suppository form if necessary. Likewise, the dipyridamole administration did not cause any difficulties and there were no cardiac or vascular complications.

Testing platelet function and the effect of various drugs in vitro may not reflect the in-vivo situation. Nevertheless, such tests served as monitors and confirmed that patients were receiving the antiplatelet drugs. The results of these studies and those of other factors related to haemostasis will be reported elsewhere.

Attempts by other workers to reduce the incidence of postoperative DVT with drugs have been aimed at changing either platelet adhesion and aggregation reactions or the coagulation mechanism. Conflicting results have been obtained with both dipyridamole ${ }^{17}$ and aspirin. ${ }^{17}{ }^{12^{-23}}$ Browse and Hall ${ }^{24}$ used $400 \mathrm{mg}$ of dipyridamole daily in an unsuccessful attempt to prevent postoperative DVT. The presence of a thrombosis was assessed on the basis of clinical signs alone, however, and this is now recognised as being an unsatisfactory method. Also, blood levels sufficient to change the platelet reactions, which are now recognised as essential in any programme aimed at preventing postoperative DVT were not achieved on the day of operation. The dose used-400 $\mathrm{mg} /$ day-resulted in a rejection rate due to side effects of $25 \%$. The side effects were mainly headache, nausea, and vomiting.

The use of aspirin and dipyridamole together to prevent postoperative DVT has not been reported before. Aspirin inhibits ADP release by aggregating and adhering platelets but does not inhibit in-vitro aggregation induced by ADP. Platelets from patients who have ingested aspirin show impaired aggregation by collagens, and the usual biphasic aggregation response to noradrenaline is inhibited. Dipyridamole, on the other hand, diminishes in-vitro aggregation induced by ADP and also enhances subsequent aggregation. It does not affect the biphasic aggregation induced by noradrenaline.

Harker and Slichter ${ }^{25}$ reported that aspirin $1 \mathrm{~g} /$ day seemed to have a synergistic reaction with dipyridamole. They studied several patients who had had artificial heart valves inserted and noted that aspirin alone did not affect the usual reduced platelet survival in these patients. This reduction in survival is due to the destruction of platelets on the surface of the artificial valve. Dipyridamole $400 \mathrm{mg} /$ day prevented the destruction of platelets 
in these patients, and lower doses of dipyridamole had a proportionately lesser effect on the improvement of platelet survival. Aspirin appeared to have a potentiating effect on dipyridamole, however, in that $1 \mathrm{~g}$, combined with $100 \mathrm{mg}$ of dipyridamole daily in a single dose instead of $400 \mathrm{mg}$ in divided doses, prevented valvular platelet consumption. We decided to assess this synergistic effect of the combined drug regimen on the in-vitro platelet reactions before and after general surgery (the results of which will be reported elsehwere) and on the incidence of postoperative DVT, which is initiated by the adhesion of platelets to damaged vascular endothelium, followed by platelet aggregation to form a platelet mass. This mass is then consolidated by the deposition of fibrin.

The dipyridamole and aspirin regimen has several attractive features. Firstly, the drugs are simple to administer and even if the patient is on nasogastric suction the tablets can be crushed and dissolved and given through the tube, the suction being turned off for two hours. Repeated platelet function studies before and after administration of the drugs showed that, no matter which technique was used, a definite effect on the platelet functions was achieved. Secondly, the potentiation of the action of dipyridamole by aspirin meant that the dose of dipyridamole could be reduced to $100 \mathrm{mg}$, and yet a considerable effect on platelet function was still detected. This greatly reduced the hypotensive and other side effects of the drug, which caused a $25 \%$ rejection rate in Browse and Hall's trial. No patient in our series had side effects that could be attributed to dipyridamole and there were no complications that could be attributed to the use of the drug combination.

The administration of low-dose subcutaneous heparin has been successful in preventing postoperative thromboembolism. ${ }^{26}{ }^{27}$ But more recently Evarts and Alfidi ${ }^{28}$ reported that the administration of low-dose subcutaneous heparin did not afford protection for patients undergoing hip surgery.

The regimen of antiplatelet drugs described (aspirin and dipyridamole) shows promise of being an effective and simple method of reducing the incidence of postoperative DVT. It is easy to administer and no complications have so far been noted.

We thank Professor R C Bennett for his advice and helpful criticism, Miss Maria Connell, our technician, for her tireless work and help, and
Boehringer Ingelheim for their generous support. The study into the diagnosis and prevention of thromboembolic disease has been supported by grants from the National Health and Medical Research Council, and the Lfe Insurance Medical Research Fund of Australia and New Zealand.

\section{References}

1 Virchow, R, Beitraege zur Experimentellen Pathologie und Physiologie, $1846,2,1$.

2 Flanc, C, Kakkar, V V, and Clarke, M B, British fournal of Surgery, $1968,55,742$.

${ }^{3} \mathrm{Kakkar}, \mathrm{V}$ V, et al, Lancet, 1970, 1, 540.

${ }^{4}$ Horowitz, R E, and Tatter, D, in Thrombosis, ed S Sherry, K M Brinkhouse, and E Genton, p 19. Washington, National Academy of Sciences, 1969.

ed S Sherry, K M Brinkhouse, and E Genton, p 19.

${ }^{5}$ Mustard, J F, et al, Thrombosis et Diathesis Haemorrhagica, 1966, 21, suppl 131.

${ }^{6}$ Bygdeman, S, Eliasson, R, and Johnson, S-R, Lancet, 1966, 1, 1301.

${ }^{7}$ Negus, D, Pinto, D J, and Brown, N, Lancet, 1969, 1, 220.

${ }^{8}$ Flute, $\mathrm{P}$ T, et al, in Thromboembolism: Diagnosis and Treatment, ed V V Kakkar and A J Jouhar, p 69. Edinburgh, Churchill Livingstone, 1972.

${ }^{9}$ McLachlin, J, and Paterson, J C, Surgery, Gynecology and Obstetrics, 1951, 93, 1 .

10 Sevitt, S, and Gallagher, N, British fournal of Surgery, 1961, 48, 475.

11 Sevitt, S, Proceedings of the Royal Society of Medicine, 1975, 68, 261.

${ }^{12}$ Nicolaides, A N, Kakkar, V V, and Renney, J T G, British fournal of Surgery, 1971, 58, 307.

${ }_{13}$ Clayton, S, and Cross, M J, fournal of Physiology, 1963, 169, 82P.

${ }^{14}$ Mustard, J F, and Packham, M A, Pharmacology Review, 1970, 22, 97.

${ }^{15}$ Emmons, P R, et al, Lancet, 1965, 2, 603.

${ }^{16}$ Sullivan, J M, Harken, D E, and Gorlin, R, New England fournal of Medicine, 1971, 284, 1391.

17 Salzmann, E W, Harris, W H, and De Sanctis, R W, New England Fournal of Medicine, 1971, 284, 1287.

${ }^{18}$ Evans, G, et al, fournal of Experimental Medicine, 1968, 128, 877.

${ }^{19}$ Kakkar, V V, et al, American fournal of Surgery, 1970, 120, 527.

20 Kakkar, V V, et al, Lancet, 1969, 2, 230.

${ }^{21}$ Scharrer, I. Schepping, M, and Breddin, K, Klinische Wochenschrift, 1969, 47, 1318.

22 Butterfield, W H J, et al, Lancet, 1972, 2, 441.

${ }^{23}$ O'Brien, J R, Modern Concepts of Cardiovascular Disease, 1973, 42, 11.

24 Browse, N L, and Hall, J H, Lancet, 1969, 2, 718.

${ }^{25}$ Harker, L A, and Slichter, S J, New England fournal of Medicine, 1970, $183,1302$.

${ }^{26}$ Kakkar, V V, et al, Lancet, 1971, 2, 669.

27 Gallus, A S, et al, New England fournal of Medicine, 1973, 288, 545.

${ }^{28}$ Evarts, C M, and Alfidi, R J, fournal of the American Medical Association, $1973,225,515$.

\title{
Factor-VIII-related antigen: measurement by enzyme immunoassay
}

\author{
A BARTLETT, K M DORMANDY, C M HAWKEY, P STABLEFORTH, A VOLLER
}

British Medical fournal, 1976, 1, 994-996

\section{Summary}

Factor-VIII-related antigen was measured, both by an enzyme immunoassay using a microplate method and by

Nuffield Institute of Comparative Medicine, Zoological Society of London, London NW1 4RY

A BARTLETT, PHD, research assistant

C M HAWKEY, PHD, head of department of haematology

A VOLLER, DSC, senior lecturer in clinical tropical medicine, London School of Hygiene and Tropical Medicine

Haemophilia Centre, Royal Free Hospital, London NW3 2QG

K M DORMANDY, MD, reader in haematology and director of haemophilia centre

P STABLEFORTH, MB, BS, senior registrar in haematology the Laurell technique, in normal people, patients with von Willebrand's disease, haemophiliacs, and obligatory haemophilia carriers. The enzyme immunoassay was simpler to perform and gave equally reliable and reproducible results. Many more assays could be carried out at any one time.

\section{Introduction}

Antisera produced by immunising rabbits with human factor VIII precipitates with a protein known as the factor-VIII-related antigen. In normal people factor VIII clotting activity and factor-VIII-related antigen are present to the same extent; in patients with haemophilia there is a deficiency of the clotting activity but the antigen levels are normal, and in most cases of von Willebrand's disease both the clotting activity and the 